\title{
Using Bioimpedance Spectroscopy to Assess Volume Status in Dialysis Patients
}

\author{
Frank M. van der Sande ${ }^{a}$ Esther R. van de Wal-Visscher ${ }^{a}$ Stefano Stuard ${ }^{b}$ \\ Ulrich Moiss ${ }^{c}$ Jeroen P. Kooman ${ }^{\mathrm{a}}$ \\ a Division of Nephrology, Department of Internal Medicine, Maastricht University Medical Center, Maastricht, \\ The Netherlands; ${ }^{b}$ Clinical and Therapeutical Governance-Care Value Management, Fresenius Medical Care \\ Deutschland, Bad Homburg, Germany; ' ${ }^{\mathrm{G}}$ lobal Research and Development, Fresenius Medical Care Deutschland, \\ Bad Homburg, Germany
}

\section{Keywords \\ Bioimpedance $\cdot$ Dialysis · Blood pressure $\cdot$ Volume control · Outcome}

\begin{abstract}
The aim of the paper is to reflect on the current status of bioimpedance spectroscopy (BIS) in fluid management in dialysis patients. BIS identifies fluid overload (FO) as a virtual (overhydration) compartment, which is calculated from the difference between the measured extracellular volume and the predicted values based on a fixed hydration of lean and adipose tissue mass. FO is highly prevalent in both hemodialysis (HD) and peritoneal dialysis (PD) patients, while levels of FO are at a population level comparable between PD patients and HD patients when measured before the dialysis treatment. Even mild levels of FO are independently related to outcome in patients on HD, PD as well as in nondialysis patients with advanced chronic kidney disease. FO is not only related to left ventricular hypertrophy (LVH) but also forms part of a multidimensional spectrum with noncardiovascular risk factors such as malnutrition and inflammation. Even after multiple adjustments, FO remains an independent predictor of mortality. BIS-assisted adjustment of dry weight in HD patients has been shown to improve hyperten-
\end{abstract}

sion control and $\mathrm{LVH}$ and has resulted in a decline in intradialytic symptomatology. On the other hand, with increased fluid removal, target weight may not always be reached due to an increase in intradialytic symptomatology, and care should be applied in target weight adjustment in fluid overloaded patients with severe malnutrition and/or inflammation. Although a reduction in hospitalization rate was suggested, the effect of BIS-guided dry weight adjustment on mortality has not yet been shown, however, although available studies are underpowered. In PD patients, results have been more equivocal, which may be partly related to differences in treatment protocols or study populations. Future large-scale studies are needed to assess the full potential of BIS.

\footnotetext{
(c) 2019 The Author(s) Published by S. Karger AG, Basel
}

\section{Introduction}

The assessment of fluid status in dialysis patients is of paramount importance. Due to the absence or reduction of renal function and the intermittency of the treatment, hemodialysis (HD) patients may experience wide variations between fluid overload (FO) and fluid depletion [1, $2]$, whereas especially anuric peritoneal dialysis (PD) pa-

\begin{tabular}{ll}
\hline KARGER & $\begin{array}{l}\text { ( } 2019 \text { The Author(s) } \\
\text { Published by S. Karger AG, Basel }\end{array}$ \\
E-Mail karger@karger.com & $\begin{array}{l}\text { This article is licensed under the Creative Commons Attribution- } \\
\text { NonCommercial-NoDerivatives 4.0 International License (CC BY- } \\
\text { NC-ND) (http://www.karger.com/Services/OpenAccessLicense). } \\
\text { Usage and distribution for commercial purposes as well as any dis- } \\
\text { tribution of modified material requires written permission. }\end{array}$
\end{tabular}

Jeroen P. Kooman

Division of Nephrology, Department of Internal Medicine University Hospital Maastricht

NL Maastricht (The Netherlands)

E-Mail jeroen.kooman@mumc.nl 
tients may be fluid overloaded due to insufficient water and sodium removal in relation to their dietary intake [3, 4]. Whereas FO is related to hypertension and left ventricular hypertrophy $(\mathrm{LVH})$, fluid depletion may result in intradialytic hypotension, tissue ischemia leading to cardiac stunning and potentially loss of white matter in the brain and loss of residual renal function (RRF) [5-7]. Therefore, an adequate assessment of fluid state in routine clinical practice is of utmost importance. Clinical examination, though invaluable due to the multidimensional assessment, may be relatively imprecise $[8,9]$. Bioimpedance spectroscopy (BIS) may serve as an easily applicable clinical tool in the assessment of dry weight in dialysis patients. Recently, a number of observational and intervention trials have shed more light on its potential clinical utility.

\section{BIS Explained Shortly}

BIS, which is one of the modifications of bioimpedance analysis (BIA), provides an estimation of intracellular water (ICW) and extracellular water (ECW) by measuring the resistance $(\mathrm{R})$ and reactance $(\mathrm{Xc}$ : or the capacitance resistance of the cell membrane) at 50 frequencies. These are translated into a Cole-Cole plot, from which the resistances at zero and infinite frequency $\mathrm{R} 0$ and $\mathrm{R} \infty$ are extrapolated, assuming that at the lowest frequencies current passes through the extracellular fluid only, whereas it passes through both intra- and ECW at high frequencies [10]. Using Hanai mixture theory adjusted for BMI, Moissl et al. [11] developed a model for the assessment of ECW, ICW, and total body water, which showed good agreement with reference methods based on tracer dilution. In a further development, Chamney et al. [12] developed a so-called three-compartment body model, which differentiates between normohydrated lean tissue mass (LTM), adipose tissue mass, and a virtual "overhydration" $(\mathrm{OH})$ compartment. This model assumes a fixed hydration of LTM and adipose tissue mass, which results in the calculation of a "normohydration weight" [12]. The $\mathrm{OH}$ compartment is calculated as the difference between the measured and the expected ECW which is expected in the sense of a working kidney [13], in which the 10th to 90 th percentile $(-1.1$ and $+1.1 \mathrm{~L})$ of the normal population is considered to represent a normovolemic situation. The definition of FO in the literature varies between a value $>1.1$ and $2.5 \mathrm{~L}$ (or a OH:ECW ratio, respectively, above 7 or 15\%), whereas fluid depletion is defined as an $\mathrm{OH}$ level below $-1.1 \mathrm{~L}$ [14]. It is important to mention that the calculation of fluid volumes with BIS depends on various assumptions. However, as will be discussed in the following paragraph, the model has shown to be remarkably accurate in predicting outcome at a population level.

\section{Prevalence of Fluid Overload}

FO, assessed by BIS, appears to be common in the dialysis population. We found severe predialytic $\mathrm{FO}(\mathrm{OH}$ $>2.5 \mathrm{~L}$ ), to be present in $27.4 \%$ of prevalent dialysis patients in a large European cohort $(n=8,883)$, whereas the prevalence increased to $66.2 \%$ when patients with mild FO $(\mathrm{OH}>1.1 \mathrm{~L})$ were included, $31.1 \%$ were normovolemic and $2.7 \%$ classified as fluid depleted (predialytic $\mathrm{OH}$ $<1.1 \mathrm{~L}$ ) [15]. In an even larger cohort of 39,566 patients, Zoccali et al. [16] found that $46.4 \%$ of patients had an $\mathrm{OH}$ :ECW index $>15 \%$ (males) or $13 \%$ (females) at the start of dialysis, which persisted in $29.5 \%$ throughout the first year on dialysis. At a population level, fluid status appears comparable between patients on $\mathrm{PD}$ and predialytic measurements in HD patients, whereas fluid levels are lower in HD after the dialysis session [17]. Ronco et al. [8] measured FO in incident PD patients and found $56.4 \%$ to be FO when a cutoff level of $1.1 \mathrm{~L}$ was used, $38.7 \%$ to be normovolemic, and to $4.9 \%$ be fluid depleted. In a large international cohort, van Biesen et al. [18] followed fluid state in PD patients over several years and found a small but significant improvement, but not a normalization, after the start of PD. Summarizing, the prevalence of FO, at least when expressed by BIS, appears to be high in the dialysis population [14].

\section{Relation to Outcome}

Various studies confirmed the relation between FO expressed by BIS and mortality. The first study was that of Wizemann et al. [19], who showed in patients that an $\mathrm{OH}$ level above $2.5 \mathrm{~L}(\mathrm{OH}: \mathrm{ECW}$ ratio $>15 \%)$ was associated with a significantly increased risk of mortality. Later on, these findings were confirmed in larger groups of patients as well as in meta-analyses $[14,16,20]$. In a report from the MONDO consortium including 8,883 patients, we found the relation with mortality to be stronger with incremental levels of FO [15] (Fig. 1), whereas Zoccali et al. [16] found that this relation was also stronger with prolonged periods of FO. FO was also shown to partly explain the paradoxical relation between low systolic BPs levels and outcome, in the sense that predialytic systolic BP below $110 \mathrm{~mm} \mathrm{Hg}$ was associated with increased mortality 


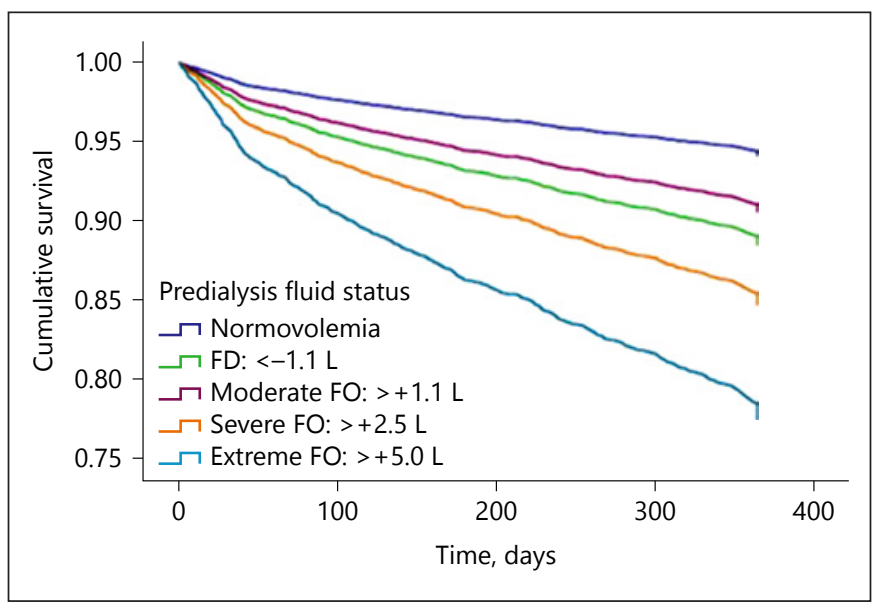

Fig. 1. Relation between pre-dialytic fluid overload and fluid depletion with outcome. From ref [15]. FD, fluid depletion.

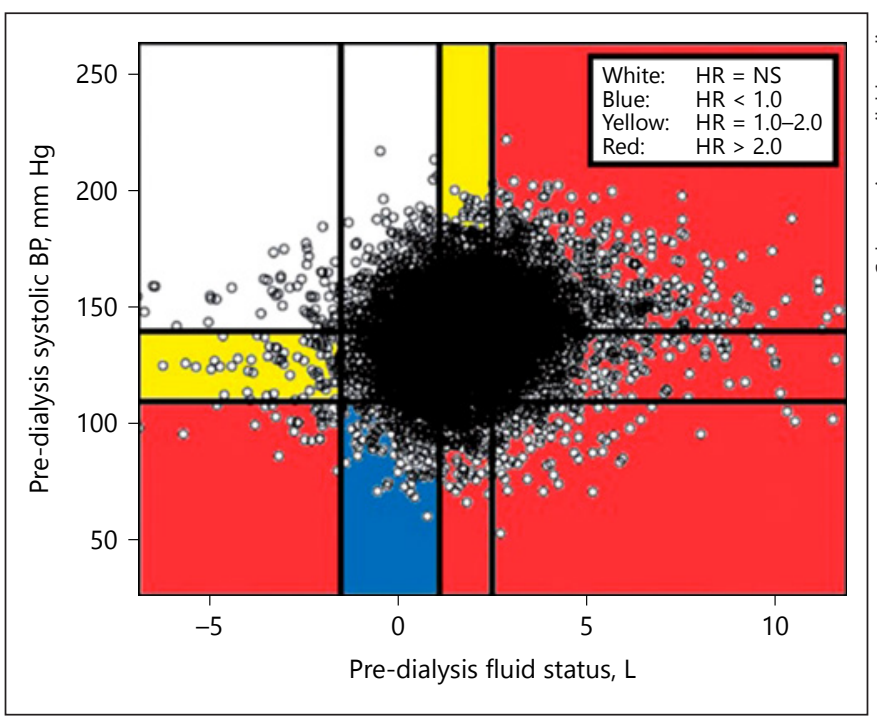

Fig. 2. The association of the combination of pre-SBP $(\mathrm{mm} \mathrm{Hg})$ and pre-dialysis FS (L) with mortality.

when combined with either predialytic FO or fluid depletion, whereas it was associated with the best survival in patients who were normovolemic [21] (Fig. 2). Importantly, already mild levels of predialytic FO (1.1-2.5 L) were already associated with increased mortality. Interestingly, 2 studies found that predialytic fluid depletion was also associated with increased mortality, although postdialytic fluid depletion appeared to be protective [15, 22 ]. This suggests that the optimal limit for dry weight assessed by BIS is quite narrow, which is of relevance that in the present cohort, only a minority of patients falls within the normovolemia targets. However, as will be dis- cussed later, it does not necessarily mean that all dialysis patients are able to reach these targets with conventional dialysis strategies. The relation between FO and mortality is also consistently found in in PD patients $[23,24]$. In this population, FO is also related to technique failure as well as a higher risk of peritonitis $[23,25,26]$. As also patients with chronic kidney disease stage $4-5$ had a higher mortality risk with even mild levels of FO [27], the relation with outcome is thus present over the entire spectrum of advanced chronic kidney disease.

\section{FO as a Component of a Multidimensional Spectrum}

Whereas FO assessed by BIS was related to traditional risk factors such as $\mathrm{LVH}$, the relation between $\mathrm{FO}$ and mortality was also observed independently from cardiac structure or function [28]. Part of the relation between FO and mortality thus also may be explained by the concomitant presence of noncardiovascular risk factors. Hung et al. [29] observed an inverse relation between FO and serum albumin, as well as a positive relation with IL-6 levels. We also observed lower levels of serum albumin and lean tissue index, as well as higher levels of C-reactive protein with incremental levels of FO [15]. Analyzing this subject in more detail, we defined the interrelation between clusters with $\mathrm{FO}(\mathrm{OH}>+1.1 \mathrm{~L}$ predialysis), inflammation (CRP levels $>6 \mathrm{mg} / \mathrm{L}$ ), and malnutrition (lean tissue index below the 10th percentile of a control population). In the majority of subjects, $\mathrm{FO}$ was present in combination with malnutrition and/or inflammation and not as a single risk factor. Notably, only $11.9 \%$ of HD patients did not have a single risk factor in this study (Fig. 3). This study also showed that the largest risk for mortality was observed in clusters where all three risk factors were present (HR 5.89) as compared to patients who had FO (HR 1.79) as single risk factor. The combination between FO and malnutrition yielded an HR of 2.53 [30]. The association between FO and malnutrition with outcome may also be reflected by the observation that patients with the highest level of FO and the lowest level of interdialytic weight gain (IDWG) had the highest mortality risk [31]. Although this may seem counterintuitive, it was shown that a decline in IDWG can precede death [32]. Thus, whereas a high IDWG may be causally related to mortality, a spontaneous decline may reflect malnutrition, showing the complex interaction of risk factors in dialysis, which are best interpreted in combination [33]. Important to stress is however that FO retains its predictive value for mortality after adjustment for multiple risk factors $[15,20]$. 
Fig. 3. Fluid overload as part of a multidimensional spectrum: association with mortality risk. From ref [30]. CRP, C reactive protein; LTI, lean tiusse index; FO, fluid overload.

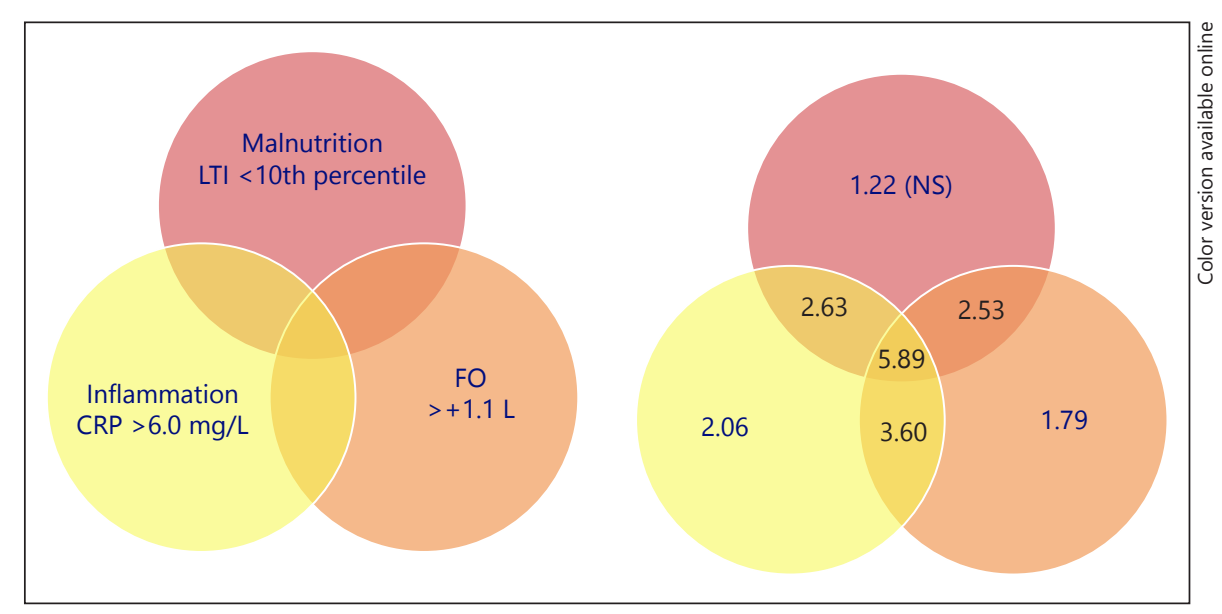

\section{Dry Weight Adjustment based on BIS}

The potential benefit of BIS-guided treatment has been assessed in both uncontrolled studies as well as randomized controlled trials (RCTs) and were recently summarized in three meta-analyses [34-36]. In the largest RCT performed so far, adjustment of dry weight according to BIS during a 1 -year period resulted in a reduction in LVH [37]. One single study observed a positive effect of BIS-guided treatment in mortality [38]. In meta-analyses, the effect of BIS-guided treatment on mortality was not significant [34], whereas it should be noted that studies performed so far were relatively small and not powered for mortality as an outcome parameter. In HD patients, studies have in general been successful in reducing FO, whereas a relatively consistent effect on an improved hypertension control was observed which was related to the magnitude of the FO correction $[20,34,39]$. In an RCT with frequent adjustment of dry weight in which (in contrast to most other studies) postdialytic FO was targeted, a reduction in intradialytic hypotension was observed as well a decrease acute FO or CVrelated events, although the primary outcome, hospitalization was not met [40]. This study used an algorithm for dry weight adjustment in patients with postdialytic $\mathrm{OH}$ levels less than -2.0 or $>1.0 \mathrm{~L}$. In the study of Hur et al. [37], as well as in a subgroup of also a positive effect of BIA-guided treatment (including different technology including BIS) on hospitalization was reported [36].

Intervention studies in PD using BIA techniques for tool-assisted dry weight adjustment have in general been less convincing, although an earlier randomized study showed an improvement in FO and blood pressure (BP) control [41]. Although based on vector BIA and not on $\mathrm{BIS}$, an RCT in PD patients, which is mentioned here be- cause it is one of the few of its kind in $\mathrm{PD}$, did not result in an overall improvement of fluid state, although a positive effect on ECW was observed in a subgroup of anuric patients [42]. The COMPASS trial, which was a RCT performed in non-anuric PD patients with RRF as the outcome parameter, did result in only minor changes in $\mathrm{OH}$ and did not reach the primary endpoint [43]. Still, the degree of FO in the included patients was mild (mean $\mathrm{OH}$ around +1.5 ) and thus the room for improvement may generally not have been that large. This in contrast to some studies in $\mathrm{HD}$ patients in which reductions in $\mathrm{OH}$ of up to $2 \mathrm{~L}$ were reported in fluid overloaded patients [44], whereas another study found that after BIS-guided dry weight adjustment $76 \%$ of patients were within or closer to their target [39]. The question is open why PD trials have so far been less successful than their HD counterparts. One of the factors may be the less frequent adjustment of dry weight (every 2-3 months) [43] as compared to monthly or even twice monthly in HD patients $[37,40]$ and (in 1 trial) the preferential inclusion of non-anuric $\mathrm{PD}$ patients [43]. Moreover, dry weight may be less easy to attain in PD as compared to HD patients, who generally visited the dialysis clinic thrice weekly and in whom ultrafiltration volume can be prescribed in an exact manner. To exploit the full potential of BIS in $\mathrm{PD}$, a larger trial with more frequent assessment of dry weight appears warranted.

\section{Potential Caveats When Adjusting Dry Weight According to BIS}

Whereas adjustment of dry weight appeared to be feasible in intervention trials [37], this is likely not feasible in all patients with the most commonly used dialysis strate- 
gies. Antlanger et al. [45] randomized patients with predialytic FO into groups treated with ultrafiltration profiling and cool dialysis. Whereas cool dialysis performed best, the incidence of adverse events with increased fluid removal was high. As ultrafiltration rate is likely the limiting factor, improvement of fluid state in some patients may be difficult to achieve without strong attention for sodium and water restriction and/or an increase in dialysis frequency and/or time. Another factor that may compromise fluid removal is hypoalbuminemia. John et al. [46] found that the excess water in hypoalbuminemic PD patients was located in the interstitial volume, whereas plasma volume was not different from normoalbuminemic subjects. Moreover, in severely malnourished patients, the distribution between ICW and ECW may also be altered, possibly due to translocation of ICW to ECW based on an osmotic shift from the intra- to the extracellular space, or abnormalities of the $\mathrm{Na}^{+}-\mathrm{K}^{+}$-ATP-ase pump have been postulated $[47,48]$. In addition, the assumption of a fixed hydration of LTM has been questioned in this patient group due to the presence of lipid within the muscle, which also holds ECW. Keane et al. [49] found that in elderly malnourished patients with normal kidney function, BIS indicated an OH level of approximately $1.1 \mathrm{~L}$. On the other hand, an earlier study using tracer dilution methods did not find differences in the hydration of lean body mass between patients with severe or mild malnutrition [50] and a comparable ECW between body groups despite a substantially lower body weight in severely malnourished patients, suggesting a "real" relative extracellular volume expansion in the presence of severe malnutrition. Still, given the fact that this excess of fluid may be difficult to mobilize as it is likely primarily stored in the interstitial, and not in the intravascular volume, a cautious fluid removal strategy appears warranted in these patients, especially in combination with low BP. Next, an interesting study showed that FO was higher in patients with megafistula flows, which could, according to the authors, be related to either the increased vascular capacitance or as a result of the hyperdynamic state [51].

An important question is whether reaching target weight would carry a risk for compromising RRF. Whereas the COMPASS trial did not find a reduction in RRF in the intervention group [43], the effects on BIS-guided treatment were, as discussed above, minor. This aspect has not been addressed in detail, although earlier studies suggested that FO is not protective with regard to the maintenance of RRF [52] and might even have detrimental effect [4]. On the other hand, also fluid depletion should be avoided. It is expected that the BISTRO trial shed more light on fluid removal strategies assisted by BIS and preservation of RRF [53]. Our personal policy, until further data are available, is to accept some degree of FO in the presence of significant RRF if the patient is normotensive and has no clinical (or biochemical) signs of FO.

In conclusion, fluid assessment by BIS is, at a population level, an accurate and powerful independent predictor of outcome even after multiple adjustments. Therefore, as it adds novel information, it might be a powerful tool for risk stratification of dialysis patients, and despite the fact that the model is based on various theoretical assumptions, its effective performance appears quite promising in this respect. From a practical point of view, in a busy dialysis clinic BIS could identify patients who are at higher risk and could as such play an important role in the integral assessment of the patient and serve as part of a quality improvement program. Evidence for the benefits of BIS-guided benefits is somewhat more limited due to lack of prospective trials and the use of varying algorithms between studies, although there is rather consistent evidence for an improvement in BP control and a suggestion for a reduction in hospitalization in HD patients. The authors argue for its interpretation in the clinical context of the patients and not for its use as the sole determinant in guiding dry weight adjustment, as in some patients complete normalization of FO may not be possible without inducing severe intradialytic symptomatology. In PD patients, although the relation between FO and with outcome was comparable to HD patients, evidence for the benefits of BCM-guided treatment is still lacking, which could be related to the study population or more limited adjustment of dry weight. Future studies should assess its relevance in larger studies.

\section{Acknowledgment}

None.

\section{Disclosure Statement}

S.S. and U.M. are employees of Fresenius MC, Bad Homburg.

\section{Funding Sources}

There is no funding source to declare.

\section{Author Contributions}

The authors jointly wrote the paper. 


\section{References}

1 Hecking M, Karaboyas A, Antlanger M, Saran R, Wizemann V, Chazot C, et al. Significance of interdialytic weight gain versus chronic volume overload: consensus opinion. Am J Nephrol. 2013;38(1):78-90.

2 Konings CJ, Kooman JP, Schonck M, Struijk DG, Gladziwa U, Hoorntje SJ, et al. Fluid status in CAPD patients is related to peritoneal transport and residual renal function: evidence from a longitudinal study. Nephrol Dial Transplant. 2003 Apr;18(4):797-803.

3 Hung SC, Lai YS, Kuo KL, Tarng DC. Volume overload and adverse outcomes in chronic kidney disease: clinical observational and animal studies. J Am Heart Assoc. 2015 May; 4(5):e001918.

4 Konings CJ, Kooman JP, Gladziwa U, van der Sande FM, Leunissen KM. A decline in residual glomerular filtration during the use of icodextrin may be due to underhydration. Kidney Int. 2005 Mar;67(3):1190-1.

5 Hassan K, Hassan D, Shturman A, Rubinchik I, Fadi $\mathrm{H}$, Shadi $\mathrm{H}$, et al. The impact of subclinical over-hydration on left ventricular mass in peritoneal dialysis patients. Int J Clin Exp Med. 2015 Apr;8(4):5890-6.

6 Konings CJ, Kooman JP, Schonck M, Dammers R, Cheriex E, Palmans Meulemans AP, et al. Fluid status, blood pressure, and cardiovascular abnormalities in patients on peritoneal dialysis. Perit Dial Int. 2002 Jul-Aug; 22(4):477-87.

7 Jansen MA, Hart AA, Korevaar JC, Dekker FW, Boeschoten EW, Krediet RT; NECOSAD Study Group. Predictors of the rate of decline of residual renal function in incident dialysis patients. Kidney Int. 2002 Sep;62(3):1046-53.

8 Ronco C, Verger C, Crepaldi C, Pham J, De Los Rios T, Gauly A, et al. Baseline hydration status in incident peritoneal dialysis patients: the initiative of patient outcomes in dialysis (IPOD-PD study) dagger. Nephrol Dial Transplant. 2015 May;30(5):849-58.

9 Time to improve fluid management in hemodialysis: should we abandon clinical assessment and routinely use bioimpedance? Clin J Am Soc Nephrol. 2013 Sep;8(9):1474-5.

10 Kyle UG, Bosaeus I, De Lorenzo AD, Deurenberg P, Elia M, Gómez JM, et al.; Composition of the ESPEN Working Group. Bioelectrical impedance analysis-part I: review of principles and methods. Clin Nutr. 2004 Oct;23(5): 1226-43.

11 Moissl UM, Wabel P, Chamney PW, Bosaeus I, Levin NW, Bosy-Westphal A, et al. Body fluid volume determination via body composition spectroscopy in health and disease. Physiol Meas. 2006 Sep;27(9):921-33.

12 Chamney PW, Wabel P, Moissl UM, Müller MJ, Bosy-Westphal A, Korth O, et al. A whole-body model to distinguish excess fluid from the hydration of major body tissues. Am J Clin Nutr. 2007 Jan;85(1):80-9.

13 Wabel P, Chamney P, Moissl U, Jirka T. Importance of whole-body bioimpedance spec- troscopy for the management of fluid balance. Blood Purif. 2009;27(1):75-80.

14 Dekker MJ, Kooman JP. Fluid status assessment in hemodialysis patients and the association with outcome: review of recent literature. Curr Opin Nephrol Hypertens. 2018 May;27(3):188-93.

15 Dekker MJ, Marcelli D, Canaud BJ, Carioni P, Wang Y, Grassmann A, et al.; MONDO Initiative. Impact of fluid status and inflammation and their interaction on survival: a study in an international hemodialysis patient cohort. Kidney Int. 2017 May;91(5):1214-23.

16 Zoccali C, Moissl U, Chazot C, Mallamaci F, Tripepi G, Arkossy O, et al. Chronic Fluid Overload and Mortality in ESRD. J Am Soc Nephrol. 2017 Aug;28(8):2491-7.

17 Devolder I, Verleysen A, Vijt D, Vanholder R, Van Biesen W. Body composition, hydration, and related parameters in hemodialysis versus peritoneal dialysis patients. Perit Dial Int. 2010 Mar-Apr;30(2):208-14.

18 Van Biesen W, Verger C, Heaf J, Vrtovsnik F, Britto ZM, Do JY, et al.; IPOD-PD Study Group. Evolution Over Time of Volume Status and PD-Related Practice Patterns in an Incident Peritoneal Dialysis Cohort. Clin J Am Soc Nephrol. 2019 Jun;14(6):882-93.

19 Wizemann V, Wabel P, Chamney P, Zaluska W, Moissl U, Rode C, et al. The mortality risk of overhydration in haemodialysis patients. Nephrol Dial Transplant. 2009 May;24(5): 1574-9.

20 Tabinor M, Elphick E, Dudson M, Kwok CS, Lambie M, Davies SJ. Bioimpedance-defined overhydration predicts survival in end stage kidney failure (ESKF): systematic review and subgroup meta-analysis. Sci Rep. 2018 Mar; 8(1):4441

21 Dekker M, Konings C, Canaud B, Carioni P, Guinsburg A, Madero M, et al. Pre-dialysis fluid status, pre-dialysis systolic blood pressure and outcome in prevalent haemodialysis patients: results of an international cohort study on behalf of the MONDO initiative. Nephrol Dial Transplant. 2018 Nov;33(11):2027-34.

22 Siriopol D, Siriopol M, Stuard S, Voroneanu L, Wabel P, Moissl U, et al. An analysis of the impact of fluid overload and fluid depletion for all-cause and cardiovascular mortality. Nephrol Dial Transplant. 2019 Jan;34(8): 1385-93.

23 O'Lone EL, Visser A, Finney H, Fan SL. Clinical significance of multi-frequency bioimpedance spectroscopy in peritoneal dialysis patients: independent predictor of patient survival. Nephrol Dial Transplant. 2014 Jul; 29(7):1430-7.

24 NgJK, Kwan BC, Chow KM, Pang WF, Cheng PM, Leung CB, et al. Asymptomatic fluid overload predicts survival and cardiovascular event in incident Chinese peritoneal dialysis patients. PLoS One. 2018;13(8):e0202203.

25 Carvalho Fiel D, Pérez-Fontán M, López Iglesias A, Bravo González-Blas L, García Gago L,
García Falcón T, et al. Persistent overhydration is associated with a significant risk of peritoneal infection by enteric pathogens in patients treated with peritoneal dialysis [La sobrehidratacion persistente asocia un riesgo significativo de infeccion peritoneal por germenes entericos en pacientes tratados con dialisis peritoneal.]. Nefrologia. 2019 Apr;pii: S0211-6995(19)30053-0.

26 Shu Y, Liu J, Zeng X, Hong HG, Li Y, Zhong $\mathrm{H}$, et al. The Effect of Overhydration on Mortality and Technique Failure Among Peritoneal Dialysis Patients: A Systematic Review and Meta-Analysis. Blood Purif. 2018;46(4): 350-8.

27 Tsai YC, Chiu YW, Tsai JC, Kuo HT, Hung CC, Hwang SJ, et al. Association of fluid overload with cardiovascular morbidity and allcause mortality in stages 4 and 5 CKD. Clin J Am Soc Nephrol. 2015 Jan;10(1):39-46.

28 Onofriescu M, Siriopol D, Voroneanu L, Hogas S, Nistor I, Apetrii M, et al. Overhydration, Cardiac Function and Survival in Hemodialysis Patients. PLoS One. 2015;10(8): e0135691.

29 Hung SC, Kuo KL, Peng CH, Wu CH, Lien YC, Wang YC, et al. Volume overload correlates with cardiovascular risk factors in patients with chronic kidney disease. Kidney Int. 2014 Mar;85(3):703-9.

30 Dekker MJ, Konings C, Canaud B, van der Sande FM, Stuard S, Raimann JG, et al. Interactions Between Malnutrition, Inflammation, and Fluid Overload and Their Associations With Survival in Prevalent Hemodialysis Patients. J Ren Nutr. 2018 Nov;28(6):435-44.

31 Hecking M, Moissl U, Genser B, Rayner H, Dasgupta I, Stuard S, et al. Greater fluid overload and lower interdialytic weight gain are independently associated with mortality in a large international hemodialysis population. Nephrol Dial Transplant. 2018 Oct;33(10): 1832-42.

32 Usvyat LA, Barth C, Bayh I, Etter M, von Gersdorff GD, Grassmann A, et al. Interdialytic weight gain, systolic blood pressure, serum albumin, and C-reactive protein levels change in chronic dialysis patients prior to death. Kidney Int. 2013 Jul;84(1):149-57.

33 Ye X, Dekker MJ, Maddux FW, Kotanko P, Konings CJ, Raimann JG, et al. Dynamics of Nutritional Competence in the Last Year Before Death in a Large Cohort of US Hemodialysis Patients. J Ren Nutr. 2017 Nov;27(6): 412-20.

34 Tabinor M, Davies SJ. The use of bioimpedance spectroscopy to guide fluid management in patients receiving dialysis. Curr Opin Nephrol Hypertens. 2018 Nov;27(6):406-12.

35 Covic A, Ciumanghel AI, Siriopol D, Kanbay M, Dumea R, Gavrilovici C, et al. Value of bioimpedance analysis estimated "dry weight" in maintenance dialysis patients: a systematic review and meta-analysis. Int Urol Nephrol. 2017 Dec;49(12):2231-45. 
36 Beaubien-Souligny W, Kontar L, Blum D, Bouchard J, Denault A, Wald R. Meta-Analysis of Randomized Controlled Trials Using Tool-Assisted Target Weight Adjustments in Chronic Dialysis Patients. Kidney Int Rep. 2019;4(10):1426-34.

37 Hur E, Usta M, Toz H, Asci G, Wabel P, Kahvecioglu $S$, et al. Effect of fluid management guided by bioimpedance spectroscopy on cardiovascular parameters in hemodialysis patients: a randomized controlled trial. Am J Kidney Dis. 2013 Jun;61(6):957-65.

38 Onofriescu M, Hogas S, Voroneanu L, Apetrii M, Nistor I, Kanbay M, et al. Bioimpedanceguided fluid management in maintenance hemodialysis: a pilot randomized controlled trial. Am J Kidney Dis. 2014 Jul;64(1):111-8.

39 Moissl U, Arias-Guillén M, Wabel P, Fontseré N, Carrera M, Campistol JM, et al. Bioimpedance-guided fluid management in hemodialysis patients. Clin J Am Soc Nephrol. 2013 Sep;8(9):1575-82.

40 Huan-Sheng C, Yeong-Chang C, Ming-Hsing H, Fan-Lieh T, Chu-Cheng L, Tsai-Kun W, et al. Application of bioimpedance spectroscopy in Asian dialysis patients (ABISAD-III): a randomized controlled trial for clinical outcomes. Int Urol Nephrol. 2016 Nov;48(11):1897-909.

41 Luo YJ, Lu XH, Woods F, Wang T. Volume control in peritoneal dialysis patients guided by bioimpedance spectroscopy assessment. Blood Purif. 2011;31(4):296-302.
42 Tan BK, Yu Z, Fang W, Lin A, Ni Z, Qian J, et al. Longitudinal bioimpedance vector plots add little value to fluid management of peritoneal dialysis patients. Kidney Int. 2016 Feb; 89(2):487-97.

$43 \mathrm{Oh} \mathrm{KH}$, Baek SH, Joo KW, Kim DK, Kim YS Kim S, et al.; Control of fluid balance guided by body composition monitoring in patients on peritoneal dialysis (COMPASS) study. Does Routine Bioimpedance-Guided Fluid Management Provide Additional Benefit to Non-Anuric Peritoneal Dialysis Patients? Results from COMPASS Clinical Trial. Perit Dial Int. 2018 Mar-Apr;38(2):131-8.

44 Machek P, Jirka T, Moissl U, Chamney P, Wabel P. Guided optimization of fluid status in haemodialysis patients. Nephrol Dial Transplant. 2010 Feb;25(2):538-44.

45 Antlanger M, Hecking M, Haidinger M, Werzowa J, Kovarik JJ, Paul G, et al. Fluid overload in hemodialysis patients: a cross-sectional study to determine its association with cardiac biomarkers and nutritional status. BMC Nephrol. 2013 Dec;14(1):266.

46 John B, Tan BK, Dainty S, Spanel P, Smith D, Davies SJ. Plasma volume, albumin, and fluid status in peritoneal dialysis patients. Clin J Am Soc Nephrol. 2010 Aug;5(8):1463-70.

47 Dicker SE. Changes in the extracellular- and intracellular- fluid phases of tissues during water diuresis in normal and hypoproteinaemic rats. Biochem J. 1948;43(3):453-61.
48 Patrick J, Reeds PJ, Jackson AA, Seakins A, Picou DI. Total body water in malnutrition: the possible role of energy intake. Br J Nutr. 1978 May;39(3):417-24.

49 Keane DF, Bowra K, Kearney K, Lindley E. Use of the Body Composition Monitor for Fluid Status Measurements in Elderly Malnourished Subjects. ASAIO J. 2017 Jul/Aug; 63(4):507-11.

50 Barac-Nieto M, Spurr GB, Lotero H, Maksud MG. Body composition in chronic undernutrition. Am J Clin Nutr. 1978 Jan;31(1):2340.

51 Tapolyai M, Faludi M, Berta K, Forró M, Zsom L, Pethö AG, et al. The association of overhydration with megafistulas in hemodialysis patients. Ren Fail. 2019 Nov;41(1):4405.

52 McCafferty K, Fan S, Davenport A. Extracellular volume expansion, measured by multifrequency bioimpedance, does not help preserve residual renal function in peritoneal dialysis patients. Kidney Int. 2014 Jan;85(1): 151-7.

53 Davies SJ, Caskey FJ, Coyle D, Lindley E, Macdonald J, Mitra S, et al. Rationale and design of BISTRO: a randomized controlled trial to determine whether bioimpedance spectroscopy-guided fluid management maintains residual kidney function in incident haemodialysis patients. BMC Nephrol. 2017 Apr 26;18(1):138. 